\title{
Problem-based Design Experience in Engineering and Education Schools via Computer Based Training Development for Lucent Technologies
}

\author{
Horace Moo-Young, Stephen Bronack \\ Lehigh University
}

\begin{abstract}
The current paper describes the partnership between Lucent Technologies Microelectronics Division in Allentown, PA and Lehigh University to develop three training modules for students in K-9. Lucent Technologies Microelectronics Division currently employs over 5,000 people in the Lehigh Valley. One of the major problems facing Lucent Technologies is community outreach. After conducting a survey of K-9 grade students in the Lehigh Valley, it was evident to Lucent that the community did not understand Lucent's business. Thus, Lucent Technologies requested the help of Lehigh University to develop prototype computer based training (CBT) modules for student in grades K-9 to teach these students about various topics in semiconductors and fiber optics. Lucent wanted to publicize and education K-9 graders on what Lucent does and the importance of the business supply.
\end{abstract}

\section{Introduction}

Applied science as practiced by professionals such as civil, electrical, chemical and mechanical engineers is firmly grounded in a process of progressive problem solvingthat is, the process of inquiry into particular scientific problems at increasing levels of complexity. However, the typical environment in which engineering students learn about such problems historically has not been conducive to progressive problem solving behaviors, and students are often unable to communicate functionally what they know to others. Accreditation boards such as Accreditation Board for Engineering and Technology (ABET) have restructured how they assess engineering and technology programs to emphasize multidisciplinary teamwork, communication skills, and life-long learning. One of the major changes in these new guidelines is the emphasis on the stakeholders (i.e., employers, alumni, students, and parents) to evaluate the program's success.

Likewise, a renewed interest in teaching and learning for understanding in education has sparked reform in colleges of education. Accrediting and advising organizations such as the Association for the Accreditation of Colleges of Teacher Education (AACTE) are encouraging colleges of education to produce educators who are problem-solvers, critical thinkers, and reflective practitioners. Unfortunately, education students are often expected to develop such attributes while engaged in design, development, and assessment activities divorced from any real contexts and real instructional problems. 
Computer-based training is gaining greater acceptance in industry to disseminate information. Network-based technologies--when utilized properly--can foster and enhance such innovative instructional practices. Simply making technologies available is not enough. Instead, technology must be designed with specific problems in mind and should support meaningful collaboration and communication with others who share a real interest in solving real problems. Instructional uses of the Internet and the WorldWide Web, for example, are more likely to succeed when they address actual needs and are grounded in sound theoretical understandings. Establishing collaborative workspaces where the development of learning communities is fostered and made more concrete for students is one such use. It is with this in mind, that Lehigh University created an innovative course in which engineering students entered into a relationship with an industry client to produce an instructional product. The completion of this product required the students to incorporate their subject matter expertise as well as to use critical thinking and problem solving skills.

\section{Literature Review}

According to Sengupta ${ }^{1}$, the very definition of engineering as an applied science is proving to be a myth. An applied science indicates a profession in which students study fundamental scientific theory and then apply it in a professional career. It is becoming clearer that an engineering education requires more than theoretical study and application. The engineer needs to be able to apply skills to unplanned problems. The current curricula offers diverse lessons on philosophical orientations, scientific content, and policies but lacks teaching of the fundamental skills required to apply these teachings in the real world ${ }^{2}$. What is required instead is a process of recursively examining the teaching situation and extracting those points which are most conducive to problemsolving.

Scardamalia and Bereiter suggest that such a process exists in the scientific community and that this process of "progressive problem solving" is an appropriate one for teachers and teacher educators to examine ${ }^{3}$. Progressive problem solving refers to the process of addressing the problems that define a particular professional domain at increasing levels of complexity, much like scientists do. Progressive problem solving is a professional attribute that helps define professional practice as well as introduce novices to the process of thinking and behaving ${ }^{3}$.

As statistical evidence may show, the amount of money that is being spent by industries on their in-house training is equal to the entire amount of money that the United States is spending on post-secondary education. This implies that engineers who endure rigorous and challenging University curricula have to be retrained before working at the professional level ${ }^{1}$. The education offered by university and industry is overlapping, thus wasting precious time in which other skills may be taught. To better explain the need for change, Sengupta likens the preparation of a doctor to that of an engineer. For

example, when a doctor enrolls in medical school, he/she gets philosophical and scientific knowledge in a classroom as well as hands on application and experience with solving real-world problems that may not have a prescribed answer. The engineering education 
needs to shift to this ideology of more hands-on problem solving experience in order to ensure that engineers will be able to solve spontaneous on the job problems ${ }^{2}$.

\section{Educational Paradigm Shift}

Based on current research it is apparent that trends are changing in education today. Unlike the lecture-based classroom, movement toward a more involved environment in which individuals are experiencing real-life problems is occurring. Ihsen et al. suggest that all education for the future has to be based on experiencing reality ${ }^{4}$. Reality in this sense is described as the state in which persons act in a professional setting solving problems that afflict the global community ${ }^{4}$. In order to experience the reality of being a professional, the techniques used to teach need to be closely examined. Currently, our static educational style transfers knowledge from the teacher or professor to the passive student. To experience implies to engage and the students are not engaged while listening to a lecture. The student needs to be actively involved in creating his or her own knowledge by trying to reach a prescribed goal.

In order for a student to experience reality, the philosophy behind teaching must be altered. The classroom is no longer an arena in which knowledge is transferred between professor and student. It has to become a nurturing environment in which the students create knowledge. This methodology follows the Constructivist Model of Learning, as reviewed by $\mathrm{Li}^{5}$. The emphasis on the creation of knowledge allows students to own their education ${ }^{6}$.

The techniques applied by the constructivist viewpoint have been included in other ventures, such as Project CIRCLE. Project CIRCLE is a "collaborative project between the University of Texas at Austin College of Education, the Austin Independent School District (AISD) and the Eanes Independent School District (EISD)" 7 . The objective of this project is to create collaborative knowledge-building communities in high schools and universities that take the constructivist approach to technology integration ${ }^{7}$. It is imperative that students are challenged not to succumb to this understanding. One way to do this is to encourage computer support for collaborative learning (CSCL). The results of using this learning approach were shown in a study done as part of Project CIRCLE. The research looked at two high schools in Austin, Texas. One school was in the inner city, the other was suburban. The study looked at three aspects of the student's behavior 1) knowledge building 1) question asking 3) self-regulation, and 4) lack of initiative. The study also examined 1) amount of teacher directives, and 2) amount of collaborative learning. Some teachers adopted the CIRCLE approach, which is heavily based on the knowledge building and constructivist approach. Other teachers were told not to use traditional teaching methods. The findings of this research that are relevant to this paper are those with regard to knowledge building and collaborative learning.

The study found that the teacher who integrated CIRCLE teaching philosophy into the curriculum created inquiry-based learning environments with high levels of questions being asked. Those who did not integrate the methodologies, but used the computer as a 
support tools, noticed an increase in knowledge building. In other words, the computer aided in attaining a constructivist classroom environment.

Although the discourse on educational style may be applied to all disciples, the research examined in this paper is targeted at engineering education. It has shown over time that different methods of learning are more effective at different times during an engineer's education ${ }^{8}$. It is with this state of mind that the proposal for Integrated Design I was created. The problem as foreseen by those involved in the creation of this innovative classroom experiences is that the university education offered to engineers is lacking the inquiry-based, real world experience that is necessary for success after graduation. Because of this lack of active participation, many students are enrolled in engineering curriculums as a stepping stone for another profession ${ }^{8}$. Engineering students are not being given the opportunities to apply their knowledge to engineering related problems in the classroom. In engineering education today, the student is often required to take core courses in physics and mathematics. These courses are generally offered by the respective departments and have no affiliation to the engineering departments. The problem with this design is that engineering students are not able to connect or integrate their learning across disciplines. In other words the students can not see how what they are learning in physics and mathematics apply to their engineering curriculum ${ }^{6}$.

One solution is to ascertain faculties that work in industry ${ }^{1}$. This is to ensure that students are seeing the field from both the textbook ideologies and an experienced mentor. The most common teaching style for design project is problem based learning (PBL). Problem based learning is a "learn by doing" pedagogy, where students are placed into groups and are given a problem to solve $9,10,11,12,13,14$. There is no formal instruction by the professor, the students are to find a solution to the problem using previous knowledge and utilizing guidance from the instructor.

\section{Project Objectives}

Lucent Technologies Microelectronics Division, in conjunction with Lehigh University aimed to develop a series of Microelectronics-related computer based training courses focusing on the age ranges of 6-9 years of age, 10-12 years of age, and 13-15 years of age over a three year period. These courses include an introduction to communication semiconductors and an introduction to communication fiber optics for each age group. In addition to the two courses, instructor's resources are designed to assist in the teaching of semiconductors and fiber optics to students in the classroom. 


\section{Design Teams}

Figure 1 illustrates the process diagram of interdisciplinary teams solving the industrial problems. The design teams were comprised of nine undergraduate students from the College of Engineering, as well as four graduate students in Education. The first cohort of Engineering students was drawn from the Lehigh's chapter of the National Society of Black Engineers. Undergraduate students from the college of engineering conducted the need assessment, learn about and provided guidance on the industry and technology, and developed the prototype software. With the permission of Lucent Technologies, the students were allowed to utilize this experience as an externship.

Graduate students in the college of education aid the group in the design, development, implementation, and assessment of pedagogical strategies. These students who participated were able to use the experience as part of their course of study via the design elective required as part of their graduate programs. If any of the participating students expressed an interest in Education, they were able to apply the credits toward a potential education minor. One advanced graduate student from the College of Engineering and one from the College of Education served as teaching assistants (TAs). The role of the TAs was to support the students, serve as a liaison between the students, the professors, and the client; and to ensure the students were on target with the development of their design.

\section{Course Outline}

Table 1 illustrates the course outlines. At the beginning of the first semester, students were given the problem statement and had an introductory client meeting. The courses were designed to limit formal faculty lectures and to provide the students with resources in an informal setting. Technical presentations were given to the students after the client requested a specific deliverable or to provide a high level overview of a particular topic.

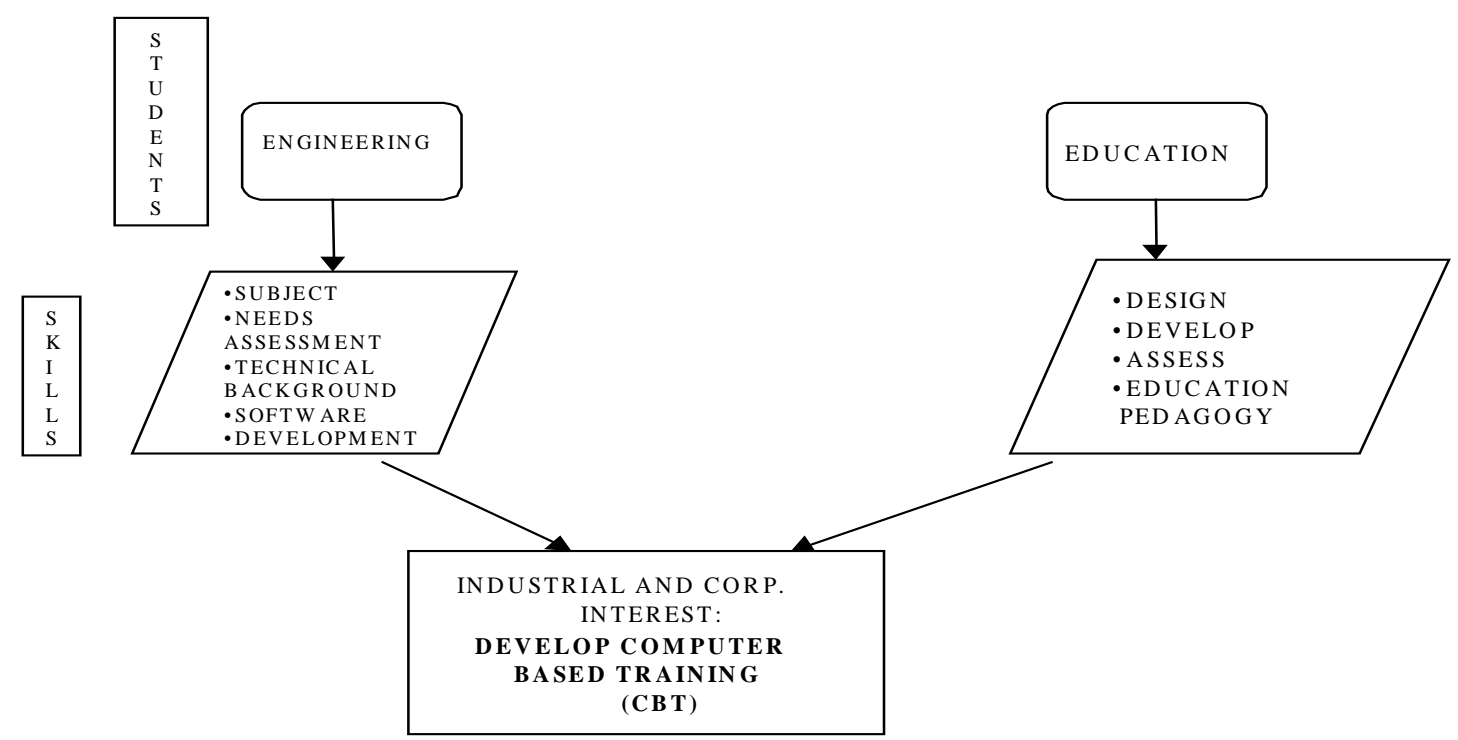

Figure 1 Process Diagram of Interdisciplinary Teams to Solve Industrial Problems 
Technical presentations covered the topics listed in the course outline in table 1. Technical presentations were delivered in two formats: classroom lectures and on-line videos streamed with PowerPoint presentations. Upon completing the technical presentations, students were provided with templates, reading material, and links to additional resources to conduct the required task. All resources were made available on the course web site that was developed using Course Info.

During the first semester, the primary deliverables included a needs assessment, defining learning objectives, interviewing subject matter experts, defining software specifications, and developing a low-fidelity prototype storyboard. To gain an understanding of why the client needs to develop the CBT, the students conducted a needs assessment. In the first month of the class, four engineers from Lucent Technologies delivered presentations to the class on fiber optics and semiconductors. The students developed a series of questions to ask the engineers to gain a greater understanding of the subject. Upon completing the interviews with the subject matter experts, learning objectives were developed for their CBT. The learning objectives provided the students with a focal point to develop the theme for their CBT. As the students developed the theme, learning objectives were modified. Students also developed the software specification utilizing the procedures outlined by Davis ${ }^{15}$. At the end of the first semester, the students

Table 1 Course Outline

\begin{tabular}{|c|c|c|}
\hline & Semester 1 & Semester 2 \\
\hline Course Titles & $\begin{array}{l}\text { Computer Based Training } \\
\text { Design }\end{array}$ & $\begin{array}{l}\text { Computer Based Training } \\
\text { Development }\end{array}$ \\
\hline \multirow{7}{*}{ Technical Presentations } & Learning Theories & Tour of Lucent \\
\hline & $\begin{array}{l}\text { Conducting Needs } \\
\text { Assessment }\end{array}$ & Hi-Fidelity Prototyping \\
\hline & $\begin{array}{l}\text { Developing Learning } \\
\text { Objectives }\end{array}$ & Educational Assessment \\
\hline & Fiber Optics Overview & Dreamweaver Tutorial \\
\hline & Lo-Fidelity Protoyping & PowerPoint Tutorial \\
\hline & Storyboarding a CBT & ColdFusion Tutiorial \\
\hline & $\begin{array}{l}\text { Developing Software } \\
\text { Specifications }\end{array}$ & $\begin{array}{l}\text { Developing Assessment } \\
\text { Strategies }\end{array}$ \\
\hline \multirow[t]{6}{*}{ Deliverables } & Needs Assessment & Developing Storyboard \\
\hline & $\begin{array}{l}\text { Defining Learning } \\
\text { Objectives }\end{array}$ & Weekly Client Meetings \\
\hline & $\begin{array}{l}\text { Subject Matter Expert } \\
\text { Interviews }\end{array}$ & \\
\hline & Client Meetings & $\begin{array}{l}\text { Present Solution to Target } \\
\text { Age Group }\end{array}$ \\
\hline & Software Specifications & $\begin{array}{l}\text { Presentation to Corporate } \\
\text { Executives }\end{array}$ \\
\hline & Lo-Fidelity Prototyping & \\
\hline
\end{tabular}


presented a low-fidelity prototype storyboard to their clients at Lucent Technologies. During the presentation, the clients provided the students with critical feedback on how to improve the product.

During the second semester, the students focused on developing the storyboard, defining assessment strategies, weekly client presentations, and developing a hi-fidelity prototype solution. To develop the storyboard, each week the teams conducted a presentation to their client to obtain feedback and approval. During the first seven weeks, the storyboard was expanded and the students aim to increase the technical focus of their solution while maintaining their creativity. The student group also developed educational exercises in their solutions to reinforce the learning. Upon obtaining the approval from their client, the groups began to prepare the hi-fidelity prototype. A final presentation was delivered to the senior level management at Lucent Technologies who provided funding for the project.

\section{Solutions}

After an initial orientation to the problem from their industrial liaison, students were provided with materials such as a company training manual or book. Teams began the production of inquiry-based activities for K-2 grade students. In year one of this program, the undergraduate students developed storyboard solutions to teach children ages 6-9 about semiconductors and fiber optics. Graduate students from the college of education guided the undergraduate students in the development of storyboards, and developed teacher guides for each solution. The solution developed on semiconductors was designed to teach children about electricity and the role that the semiconductors industry plays in electronic devices. The fiber optic solution was developed to illustrate the importance of light in fiber optic communication. Lucent Technologies utilized the student's solutions to develop the final product for dissemination to K-2 grade schools. The final design specification provided to the external vendor were as follows:

- Internet browser capable (Internet Explorer 3.0 and higher, and Netscape 4.0 and higher

- 800 x 600 resolution and higher (The course must be at full screen at all times and should never scroll. If the resolution is higher than $800 \times 600$ the content needs to either expand full screen or be centered. If centered, the empty space should be filled with an appropriate tiled image.)

- CD-ROM based. Although these courses are intended for distribution on CD-ROM, the courses will also be run over the web or be downloaded from a web site. The course on the CD-ROM should not need to connect to the Internet.

- Installation. In the case that a plug-in is required, it needs to be auto-installed from both the CD-ROM and web applications.

\section{Summary}

This paper describes an innovative partnership between Lucent Technologies and Lehigh University to develop computer based training modules for K-12 community outreach. Engineering and education students worked together to produce CBT modules on fiber 
optics and semiconductors. This innovative design experience took place over two semesters. Undergraduate engineering students developed the storyboard and hi-fidelity prototype solutions, and graduate students from the college of education developed teacher's notes for the modules. Lucent Technologies took the final student solutions and utilized an external vendor to develop the modules.

\section{Recommendation for Future Research}

One of the major issues that this course aimed at addressing was stakeholdership. The authors conducted a study to evaluate and assess the attitudes and behaviors of the students with regards to their understanding of stakeholdership, ability to think critically, and development of problem solving skills. At the time of writing this article, the authors were still evaluating the students' responses.

\section{Acknowledgement}

The views expressed in this paper are sole those of the authors. The authors would like to thank Garnell Bailey, Dwayne Rideout, Randy Riggs, Patricia Chila, and Scott Harkey of Lucent Technologies Microelectronics Division for their financial support. The authors would also like to thank the Ventures Program at Lehigh University for its financial support.

\section{Bibliography}

1. SenGupta, S. The center for engineering education and practice: rethinking engineering education. Mtropolitan Universitis. 97-109 (1997).

2. Pudlowski, Z.J. (1995) Major issues in developing modern curricula in engineering and technology education. European Journal of Engineering Education_20 (4). 403-414. (1995).

3. Scardamalia, M. \& Bereiter, C. Computer support for knowledge-building communities. The Journal of Learning Science. 3 (3). 265. (1993).

4. Ihsen, S., Isenhardt, I, \& Steinhagen De Sanchez, U. Creativity, complexity and self-similarity: the vision of the fractal university. European journal of Engineering Education 23 (1). 13-22 (1998).

5. Li, H. Information-technology-based tools for reengineering construction engineering education. Computer Applications in Engineering Education 6 (1). 15-21. (1998).

6. Tornkvist, S. Creativity: can it be taught? The case of engineering education. European Journal of Engineering Education 23 (1). 5-12. (1998).

7. Shell, D. Effects of collaborative, computer-supported, knowledge-building communities on high school students' knowledge building and intentional learning. Paper presented at the Annual Conference of the American Educational Research Association (New York, NY, April 8-12, (1996).

8. Lutz, C. F. \& Schachterle, L. Projects in undergraduate engineering education in America. European journal of Engineering Education 21 (2). 207-214 (1996).

9. Arthur, M.A. \& Thompson, J.A. Problem-based learning in a natural resources conservation and management curriculum: A capstone course. Journal of Natural Resources and Life Science. Vol. 28. p. 97. (1999).

10. Baker, C.M. Using problem-based learning to redesign nursing administration masters programs. The Journal of Nursing Administration. Vol. 30. No. 1. p. 41. (2000).

11.Burruss, J.D. Problem-based learning. Science Scope. Vol. 22. No. 6. p. 46. (2000).

12. Mierson, S. Stories from the field: problem-based learning from a teacher's and a student's perspective. Change: the Magazine of Higher Learning. Vol. 32. No. 1. p. 20. (2000).

13. Smith, C.A. "Problem based learning. Biomedical Education. Vol 27. No. 4. p. 214. (1999).

14. Woods. Problem-based learning and problem solving. Problem-Based Learning in Education for the Professions. Boud, D. (Ed) HERDSA, Sydney. (1985). 
15.Davis, A.M. Software requirements: objects, functions and states (Revised Edition). Prentice Hall, Saddle River. (1993).

\section{HORACE MOO-YOUNG}

Horace Moo-Young is an Assistant Professor of Civil and Environmental Engineering at Lehigh University. Dr. Moo-Young teaches course in Environmental Engineering. He received his B.S. from Morgan State University, and his M.S. and Ph.D. from Rensselaer Polytechnic Institute. Horace received the Andersen Consulting Faculty Fellowship for Excellence in Education Programs (ACFFEEP). As a result of this award, Horace has developed the learning theory called Goal Oriented Learning Environments (GOLE), which implements the goal-based scenario into the university environment.

\section{STEPHEN BRONACK}

Stephen Bronack is an Assistant Professor in the College of Education at Lehigh University. Dr. Bronack received his B.S. and M.A. degree from Appalachian State University and his Ph.D. degrees from the University of Virginia. Dr. Bronack specializes in the technology based teacher education. 